\title{
Analysis of Equilibrium Data for Cesium Ion Exchange of Hanford CC and NCAW Supernatant Liquid--Status Report
}

D. E. Kurath

L. A. Bray

K. P. Brooks

C. D. Carlson

A. Y. Kim

April 1996

Prepared for the U.S. Department of Energy under Contract DE-AC06-76RLO 1830

Pacific Northwest National Laboratory Richland, Washington 99352 
PNNL-11117

UC-810

Project Technical Information

\title{
Analysis of Equilibrium Data for Cesium Ion Exchange of Hanford CC and NCAW Supernatant Liquid--Status Report
}

\author{
DE Kurath \\ LA Bray \\ KP Brooks \\ CD Carlson \\ AY Kim
}

April 1996

Prepared for

the U.S. Department of Energy

under Contract DE-AC06-76RLO 1830

Pacific Northwest National Laboratory

Richland, Washington 99352

Reprint of historical document TWRSPP-93-051, dated 1993. Data, formatting, and ocher conventions reflect standards at the original date of printing. Technical peer reviews and editorial reviews may not have been performed. 


\title{
DISCLAIMER
}

This report was prepared as an account of work sponsored by an agency of the United States Government. Neither the United States Government nor any agency thereof, nor Battelle Memorial Institute, nor any of their employees, makes any warranty, express or implied, or assumes any legal liability or responsibility for the accuracy, completeness, or usefulness of any information, apparatus, product, or process disclosed, or represents that its use would not infringe privately owned rights. Reference herein to any specific commercial product, process, or service by trade name, trademark, manufacturer, or otherwise does not necessarily constitute or imply its endorsement, recommendation, or favoring by the United States Government or any agency thereof, or Battelle Memorial Institute. The views and opinions of authors expressed herein do not necessarily state or reflect those of the United States Government or any agency thereof.

\author{
PACIFIC NORTHWEST LABORATORY \\ operated by \\ BATTELLE MEMORIAL INSTITUTE \\ for the \\ UNITED STATES DEPARTMENT OF ENERGY \\ under Contract DE-AC06-76RLO 1830
}

This document was printed on recycled paper. 
This report contains the results of a partial analysis and correlation of a large amount of equilibrium data obtained for cesium ion exchange. Data from the testing of the organic resins CS-100, a phenolic-carboxylic acid resin produced by Rohm and Haas, and a resorcinol-formaldehyde resin with NCAW and $\mathrm{CC}$ waste simulants were assessed. The isotherms that were considered for correlating the data include the Langmuir, the Freundlich, and a combination Langmuir-Freundiich isotherm. These correlations are being developed to provide equations that can be used with models for assessing column behavior and to provide correlations that will allow prediction of the equilibrium performance of the two resins with wastes of different compositions.

The following results were obtained;

- The isotherms obtained provide a simple relationship between the cesium in solution and the cesium on the resin that can be used in modeling column behavior.

- The equilibrium data obtained for the CS-100 resin and for the resorcinol-formaldehyde resin below a cesium concentration of $1 \mathrm{E}-04 \mathrm{M}$ were well represented by the Freudlich isotherm.

- A more complicated Langmuir-Freundlich isotherm is required to model the full range of equilibrium data obtained for the resorcinot-formaldehyde resin.

- The Langmuir isotherm did not fit the equilibrium data very well and is not recommended for use.

- The cesium selectivity of the CS-100 resin decreases as temperature increases.

- The cesium selectivity of the CS-100 resin is a weak function of sodium concentration over the range of $3-5 \mathrm{M}$ sodium in that it decreases slightly as sodium concentration increases.

- The cesium selectivity of the resorcinol-formaldehyde resin exhibits almost no functional dependence on either temperature $\left(10^{\circ} \mathrm{C}-40^{\circ} \mathrm{C}\right)$ or sodium $(3-5 \underline{M})$. 


\section{CONTENTS}

SUMMARY ............................ . . i . . . . . . . .

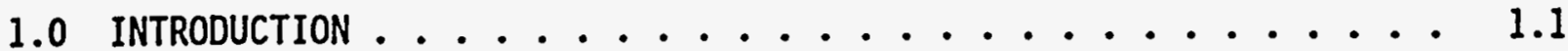

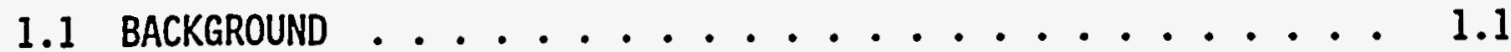

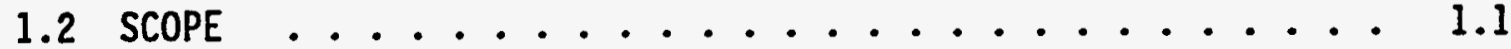

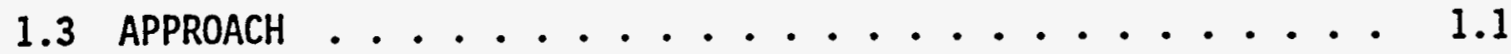

2.0 THEORY . . . . . . . . . . . . . . . . . . . . . 2.1

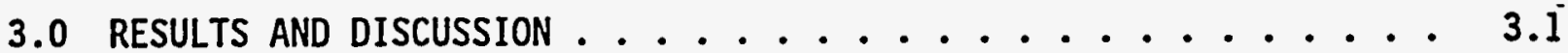

3.1 CS-100 Equilibrium Data - Freundlich Isotherm . . . . . 3.1

3.2 Resorcinol-Formaldehyde Equilibrium Data - Langmuir-Freundlich Isotherm ................ 3.4

4.0 REFERENCES . . . . . . . . . . . . . . . . . . 4.1

APPENDIX A - CS-100 Equilibrium Data - Freundlich Isotherm . . . . . A.1

APPENDIX B - Resorcinol - Formaldehyde Equilibrium Data - Langmuir-Freundlich Isotherm .......................... B.I 


\subsection{INTRODUCTION}

\subsection{BACKGROUND}

It is presently planned to use ion exchange to remove $\mathrm{Cs}-137$ from the alkaline supernates and sludge wash solutions, dissolved saltcakes and other solutions that may be generated as part of tank waste treatment. As the first step in selecting the material to be used a large number of batch contacts were performed with various ion exchange materials and waste simulants containing varying amounts of cesium. These data have been previously reported in Bray et. a7., 1992.

\subsection{SCOPE}

The scope of this effort involves the analysis and correlation of the equilibrium data obtained with NCAW and CC waste simulants using the two organic resins CS-100, a phenolic-carboxylic acid resin produced by Rohm and Haas and the resorcinol-formaldehyde (BIB-DJ) resin developed at Savannah River. The goal of the work is twofold;

- to provide equations that represent the equilibrium data that can be used in modeling the column behavior, and

- to provide correlations that will allow prediction of the equi7 ibrium performance of the two resins with wastes of different compositions.

\subsection{APPROACH}

The ion exchange system is a complex system that is difficult to rigorously model due to the large number of components in the waste and the nonideal thermodynamic behavior of the concentrated ionic solutions and of the ion exchangers. He attempted to use the simplest method first and gradually progress to more complex models. The first model attempted was the simple mass action law. This was followed by converting the equilibrium data into isotherms. Various isotherm models were tried in succession: the Langmuir (Langmuir, 1916), the Freundlich (Freundlich, 1926) and a combination Langmuir-Freundlich (LF) isotherm (Koble and Corrigan, 1952). 


\subsection{THEORY}

The resin and the solution can be thought of as two separate phases. The liquid phase is a high ionic strength alkaline solution with a variety of different ions (Table 1). The two organic resins are made up of 1 inear polyelectrolytes held together with crosslinks between the polymer chains. In the absence of these crosslinks the polymer would dissolve in the liquid resulting in a homogenous solution. However, the crosslinks hold the resin particles together with the result that the resin can be thought of as a separate liquid phase. Some of the electrolyte diffuses into the bead but the composition is generally different than that of the bulk solution.

For the following analysis we have assumed that the system can be treated as a binary system involving sodium and cesium only. Many of the tank wastes contain significant amounts of potassium so this analysis may need to be modified to account for this. In a multi-ion solution that exhibits ideal solution behavior, the binary exchange equilibrium coefficients (separation factor) would be identical to those for the respective binary systems. The actual system may not be quite so well behaved because the binary equilibrium coefficients are affected by the composition of the solvent in the resin and this depends on the properties of the counter-ions that are present in the resin.

The cesium exchange reaction with sodium may be written as;

$$
\overline{N a}+\mathrm{Cs} \longleftrightarrow \mathrm{Na}+\overline{\mathrm{Cs}}
$$

where the bar refers to the resin.

One common way of representing equilibrium data is with the separation factor which is defined as follows;

$$
\alpha=K_{\text {eq }}=\frac{[\mathrm{Cs}]_{s}[\mathrm{Na}]_{1}}{[\mathrm{Cs}]_{1}[\mathrm{Na}]_{s}}
$$


TABLE 1. Composition of Waste Simulants(a)

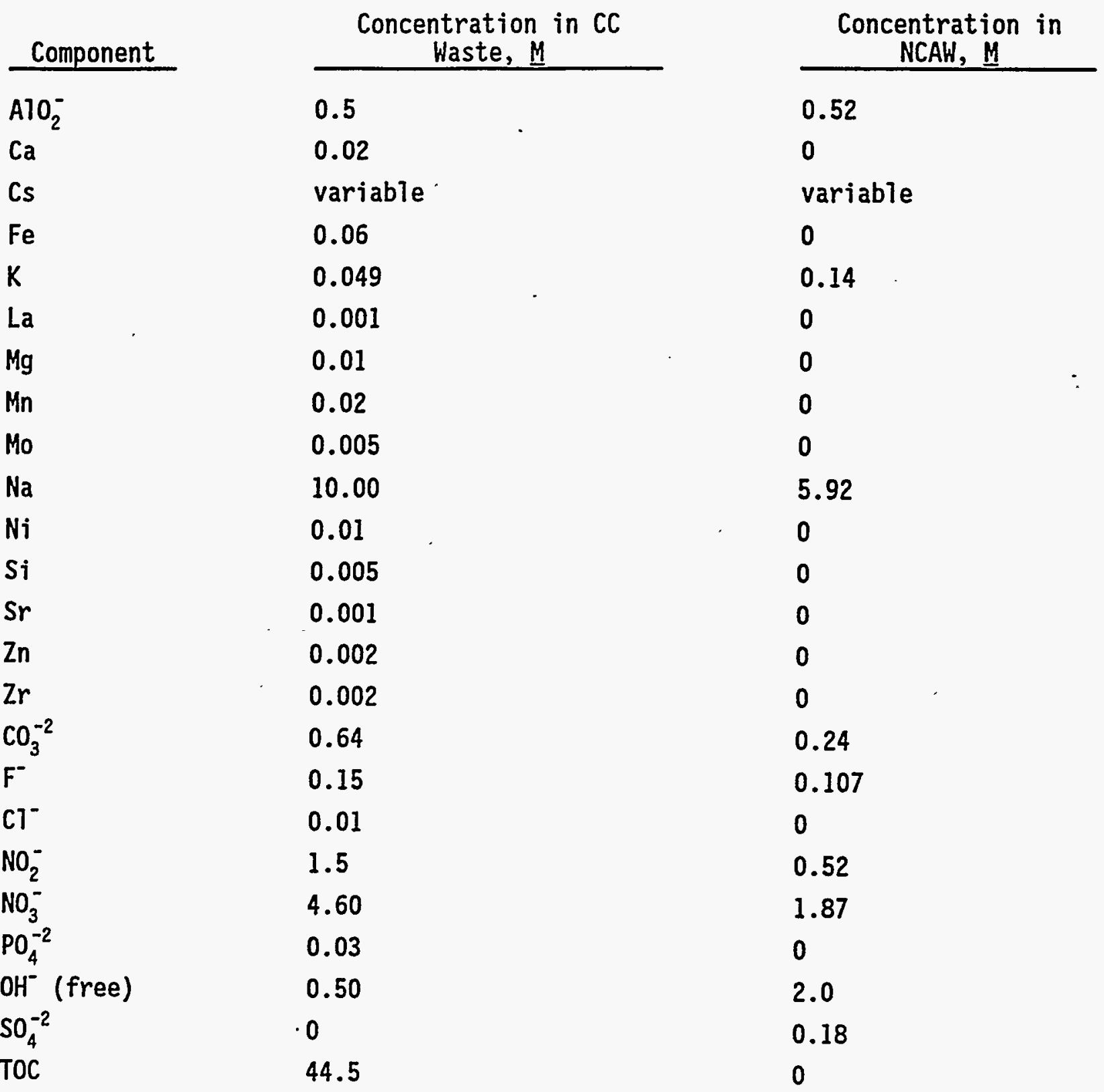

(a) Concentrations are for stock solutions. 
where; $K_{e q}=$ the equilibrium constant assuming ideal solution behavior, $[\mathrm{Cs}]_{1}=$ the concentration of cesium in solution $[=] \mathrm{M}$,

$[\mathrm{Na}]_{1}=$ the concentration of sodium in solution $[=] \mathrm{M}$,

$[C s]_{s}=$ the concentration of cesium in the resin $[=] \mathrm{M}$,

$[\mathrm{Na}]_{s}=$ the concentration of sodium in the resin $[=] \underline{M}$.

For the exchange of monovalent ions such as sodium and cesium the separation factor is identical to the equilibrium coefficient assuming ideal solutions. According to the literature these actually vary by perhaps a factor of 2 to 4 because of nonideal solution behavior (Helfferich, 1962).

Equation 1 can be rearranged to give Equation 2;

$$
[C s]_{s}=\frac{Q K_{e q}[C s]_{1}}{\left\{[\mathrm{Na}]_{1}+K_{e q}[C s]_{l}\right\}}
$$

where; $Q=$ the total ion exchange capacity $[=] \underline{M}$.

The fact that the total ion exchange capacity of the resin is equal to the sum of the concentrations of the sodium and cesium on the resin was used to obtain Equation 2.

This equation is in the same form as that of the Langmuir isotherm. For gases the Langmuir isotherm corresponds to the assumption that the adsorption. takes $\mathrm{place}$ on a homogenous surface with no interaction between adsorbed molecules. In ion exchange the isotherm corresponds to a resin particle that is assumed to be homogenous and the exchanged ions have no interaction with each other.

At low concentrations of cesium, equation 2 reduces to a linear function of $[\mathrm{Cs}]_{1}$ (Equation 3) which has a slope of 1 on a $\log -\log$ plot.

$$
[\mathrm{Cs}]_{\mathrm{s}}=\frac{\mathrm{Q} \mathrm{K}_{\mathrm{eq}}[\mathrm{Cs}]_{1}}{[\mathrm{Na}]_{1}}
$$


At high concentrations of cesium, the concentration of cesium on the solid becomes constant as the ultimate capacity of the resin is approached (Equation 4).

$$
[c s]_{s}=Q
$$

To determine the values of $K_{\text {eq }}$ and $Q$, Equation 2 can be rearranged to the following form;

$$
\frac{1}{[\mathrm{Cs}]_{s}}=\frac{[\mathrm{Na}]_{1}}{Q K_{\mathrm{eq}}[\mathrm{Cs}]_{1}}+\frac{1}{Q}
$$

A plot of $1 /[C s]_{s}$ vs $1 /[C s]_{1}$ results in an intercept of $1 / Q$ and a slope of $[\mathrm{Na}]_{1} / K_{\text {eq }} Q$. $Q$ can be determined directly from the intercept and $K_{\text {eq }}$ can be determined from the slope, the estimated value of $Q$ and the known sodium concentration. Note that with the very low cesium concentrations used in the experiments, the sodium concentration is essentialiy constant.

We actually used a nonlinear curve fitting routine based on the Marquardt-Levenberg algorithm that is part of the SigmaPlot graphing software. The routine allowed us to enter Equation 2 as given and specify which parameters to fit. The algorithm determined the specified parameters $\left(Q, K_{e q}\right)$ such that the sum of the squares of differences between the dependent variable $\left([\mathrm{Cs}]_{\mathrm{s}}\right)$ in the equation and the data was minimized subject to a specified weighting function. He used a weighting function of $1 / y^{1.5}$ where $y$ was the cesium concentration on the solid to multiply the square of the differences. This gave the data, at low concentrations of cesium more weight, allowing a better fit for the correspondingly small differences between the data and the curve fit. Without this weighting function, only one or two data points at the highest cesium concentrations were significant.

Unfortunately Equation 2 did a poor job of fitting the data at low cesium concentrations because the slope of the data on a $\log -70 \mathrm{log}$ plot is not 1 
but actually somewhat less than 1. This can be seen in Figure 2.1 where one set of actual data can be seen to lie above the Langmuir curve fit.

The linear portion of the actual data in Figure 2.1 suggests that the Freundlich equation can be used to fit the data. The general equation is;

$$
[C s]_{s}=K[C s]_{1}^{n}
$$

where $K=$ the proportionality constant determined by the curve fit

$n=$ the exponent determined by the curve fit.Taking the logarithm of . both sides of the equation gives;

$$
\ln [C s]_{s}=\ln [K]+n \ln [C s]_{1}
$$

A graph of $[C s]_{s}$ vs $[C s]_{l}$ gives a straight line on a $\log -\log$ plot for this isotherm.

The exponent $n$ can be determined from the slope and the constant $K$ can be determined from the intercept. Again we used the nonlinear curve fitting routine in SigmaPlot. Unfortunately the Freundlich isotherm only fits the data at low concentrations of cesium since it does not account for the fact that the ion exchange materials have a finite capacity. Equation 6 was used to fit the data for the CS-100 resin.

The BIB-DJ resin has a much greater selectivity for cesium and exhibited saturation behavior at higher concentrations of cesium. This indicated that a significant fraction of the ion exchange sites were occupied by cesium. Consequently we decided that the a combination of the Langmuir and Freundlich 


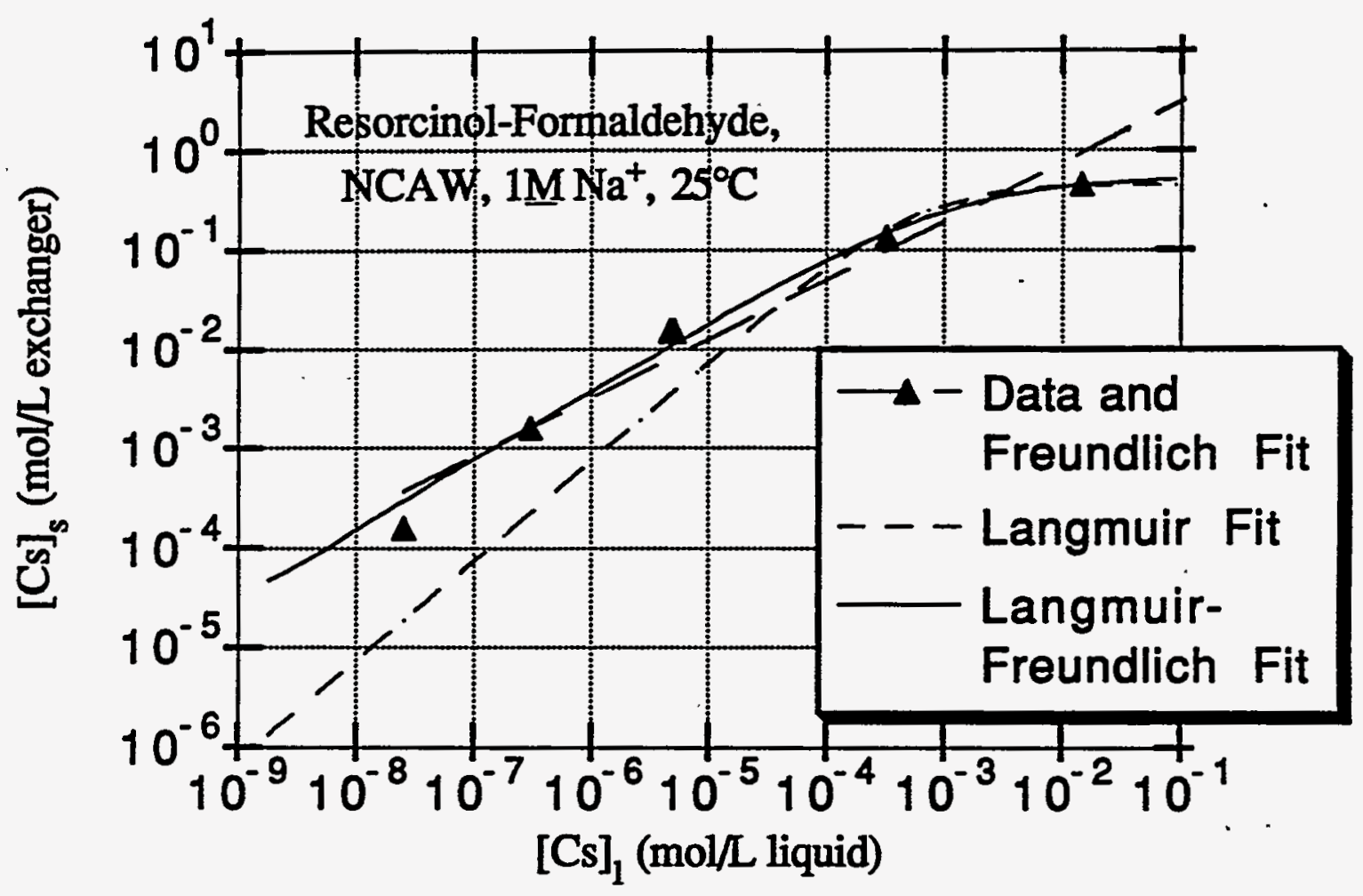

FIGURE 2.1. Comparison of Isotherms 
isotherms would model these isotherms. The Langmuir-Freundlich (L-F) isotherm equation is given as follows;

$$
[C s]_{s}=\frac{K_{1}[C s]_{7}^{m}}{k_{2}+[C s]_{7}^{m}}
$$

where $K_{1}, K_{2}$ and $m$ are the parameters determined by the curve fitting routine.

This equation contains characteristics of both the Langmuir and Freundlich isotherms. At low concentrations of cesium the equation reduces to the Freundlich isotherm, and at high concentrations it reduces to the 1 imiting case of the Langmuir isotherm (equation 4). This equation was used to fit the data from the BIB-DJ resin only, since the CS-100 data was all in a range modeled by the Freundlich isotherm.

The L-F equation can not be readily rearranged into a form in which the parameters can be easily determined graphically. Consequently the 3 parameters in the equation were determined using the nonlinear curve fitting routine in SigmaPlot. 


\subsection{RESULTS AND DISCUSSION}

Some of the results of the data analysis are contained in this section although due to the large number of graphs the actual data and curve fits can be found in the Appendices $A$ and $B$.

\subsection{CS-100 Equilibrium Data - Freundlich Isotherm}

An example of the data and the fit of the Freundlich isotherm is shown in Figure 3.1. In general, all of the data obtained for the CS-100 resin fit well using the Freundlich isotherm. The experimental conditions investigated did not approach the ultimate loading capacity of the resin. Figure 3.1 (a) illustrates that the cesium selectivity of the CS-100 resin decreases as the temperature increases. Figure 3.1 (b) illustrates that the cesium selectivity of the CS-100 resin decreases slightly as the sodium concentration increases a) though the functional dependence is weak.

The variation of the Freundlich isotherm parameters $K$ and $n$ are shown in Figure 3.2 for the CS-100 data as a function of sodium and temperature. The parameter $K$ can be seen to decrease with-temperature and sodium concentration. This is consistent with general observations of the equilibrium data which indicates that the selectivity of the CS-100 resin for cesium decreases with an increase in sodium concentration and temperature. The parameter $n$ can be seen to decrease slightly with an increase in sodium although it is relatively constant at a sodium concentration greater than $1 \underline{M}$. The parameter $n$ also exhibits a s7ight increase with temperature. In general, the parameters exhibit the same trends in temperature and sodium concentration for the two waste types.

For comparison, a value of 0.71 was reported (Samanta, 1992) for $n$ with a solution containing $1.0 \mathrm{M} \mathrm{NaNO}_{3}$, and $0.1 \mathrm{M} \mathrm{NaOH}$. The $n$ 's obtained in the two different sets of experiments are reasonably similar and the differences could be due to the complex solution mixture used in our experiments or to the fact that different resin batches were used that were possibly produced with different methods. 


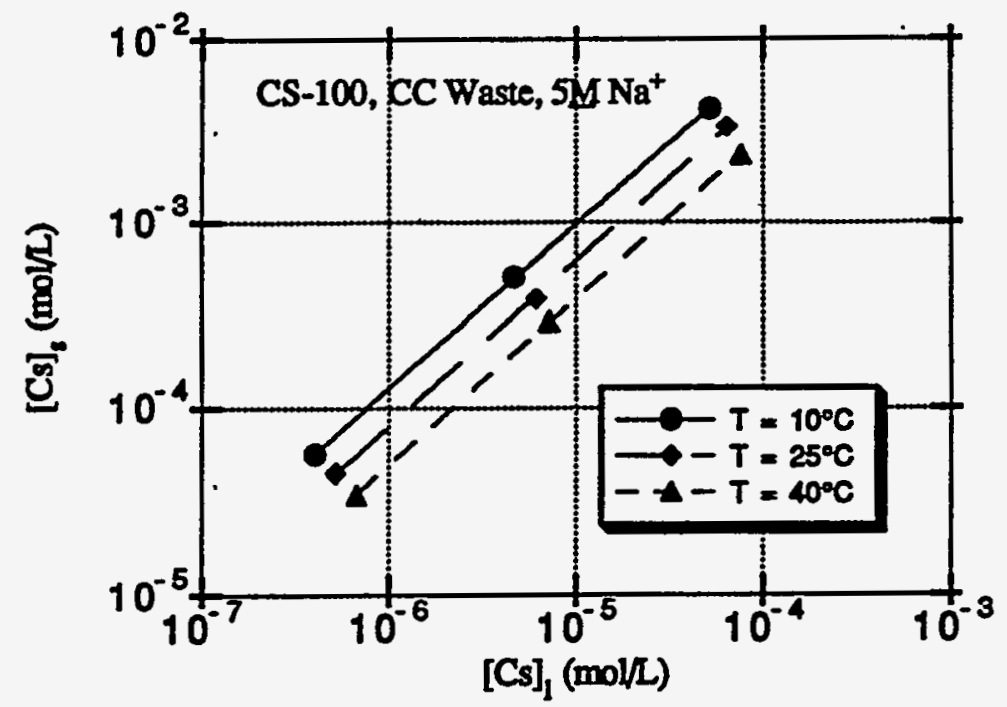

(a) Effect of Variation of Temperature

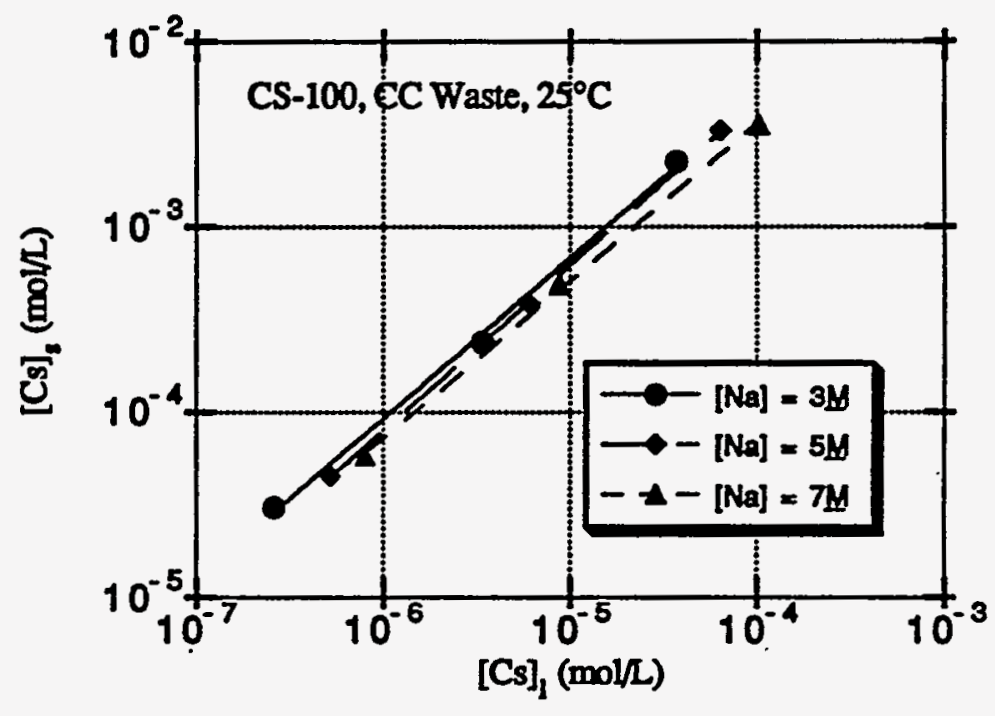

(b) Effect of Variation of sodium concentration

Figure 3.1. Freundlich Isotherm Fit of CS-100 Data. 


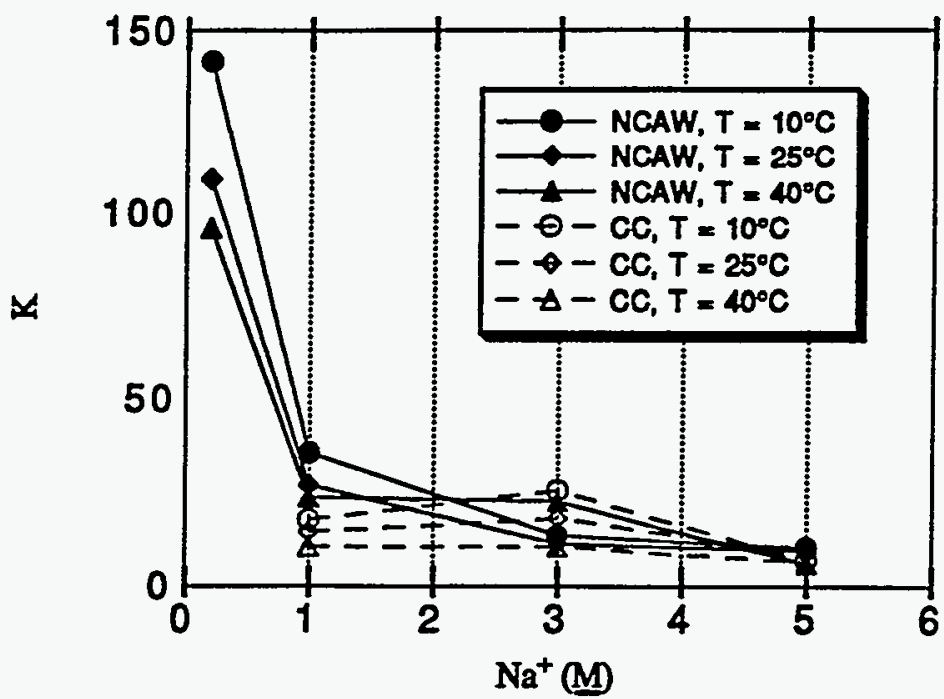

(a) Variation of $\mathrm{K}$

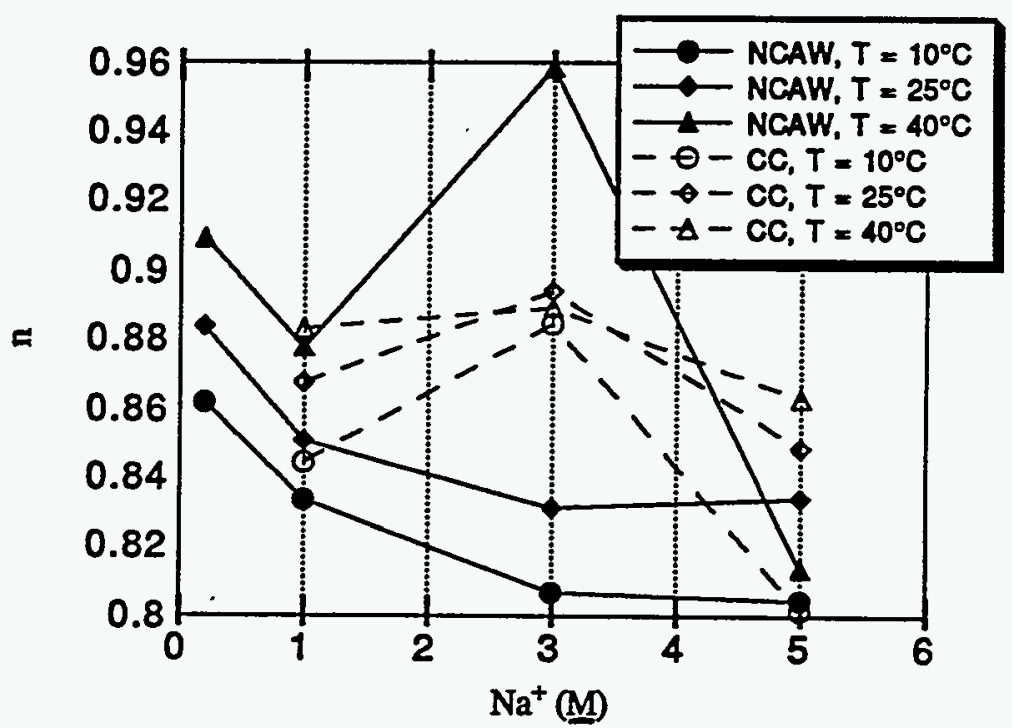

(b) Variation of $n$

Figure 3.2. Variation of Freundlich parameters. 


\subsection{Resorcinol-Formaldehyde Equilibrium Data - Langmuir-Freundlich Isotherm}

An example of the data and the fit of the $L-F$ isotherm is shown in Figure 3.3 for the BIB-DJ resin as a function of sodium and temperature. The graphs for the remaining data and curve fits can be found in Appendix B. Both graphs illustrate that the slectivity of the BIB-DJ resin exhibits almost no functional dependence on either temperature or sodium concentration.

The variation of the $L-F$ isotherm parameters $K_{1}, K_{2}$ and $m$ are shown in Figure 3.4 as a function of sodium concentration and temperature. For the data obtained with the NCAH, $K_{1}$ and $K_{2}$ increase with an increase of sadium concentration and exhibit a slight decrease with increasing temperature. The parameter $m$, decreases slightly as the sodium concentration increases although it is relatively constant above a sodium concentration of $1 M$ and exhibits no discernable trend with temperature. For the data obtained with the CC waste, $K_{1}$ and $K_{2}$ are relatively independent of the sodium concentration and exhibit no discernable trend as a function of temperature. The parameter $m$ increases slightly as a function of sodium concentration. The values of $\dot{m}$ obtained for both sets of waste are similar but not identical. The values of $K_{1}$ and $K_{2}$ show no correlation between the two waste types.

\section{Additional Analysis}

The following items will be investigated in FY-94.

- Develop a correlation for the temperature dependance of the empirical parameters. This is expected to be in the form of the Arrhenius equation.

- Investigate the possibility of developing a single empirical equation that accounts for differences in sodium and temperature. This will most likely only be possible in the region modeled by the Freundich isotherm. The large variations in the empirically determined parameters for the Langmuir-Freundlich isotherm indicates that it will be difficult to derive parameters that fit a wide variety of wastes.

- Develop a correlation for the dependence of the empirical parameters on the sodium concentration.

- Investigate the impact of potassium on the equilibrium behavior of both resins. 


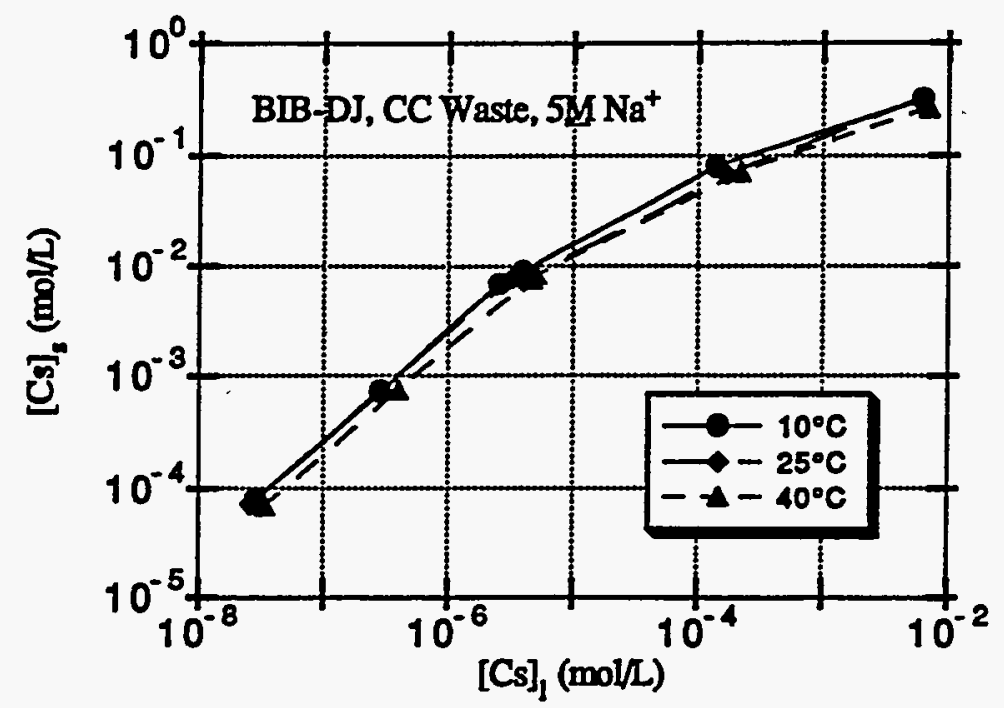

(a) Effect of Variation of Temperature

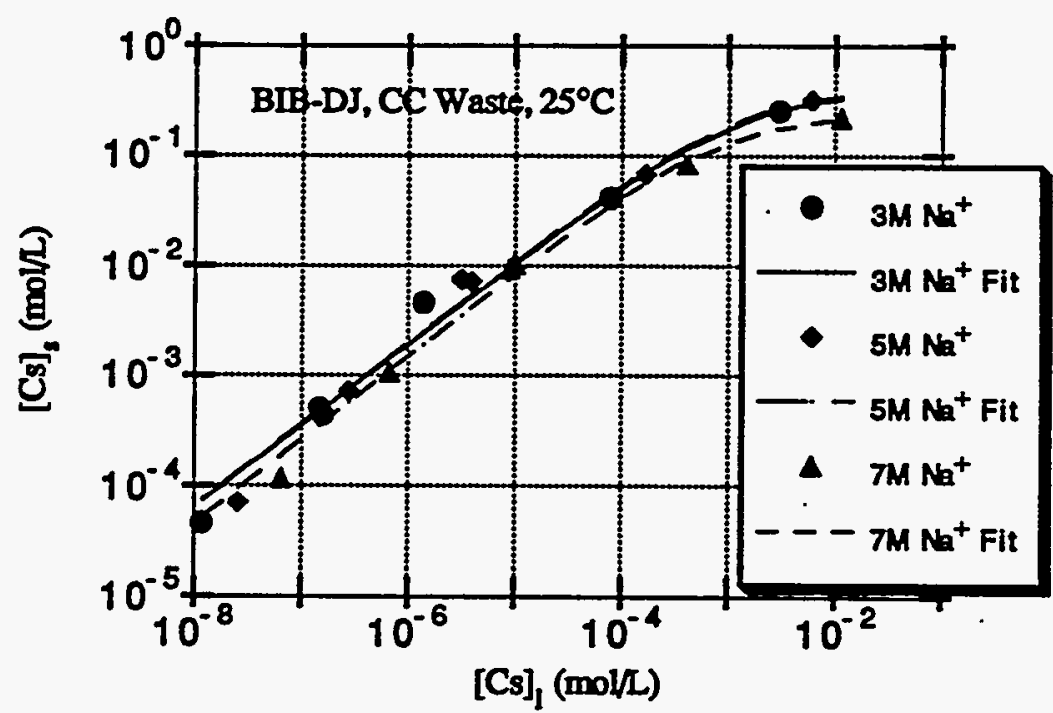

(b) Effect of Variation of Sodium Concentration

Figure 3.3. L-F Isotherm Fit of Resorcinol-Formaldehyde Data. 


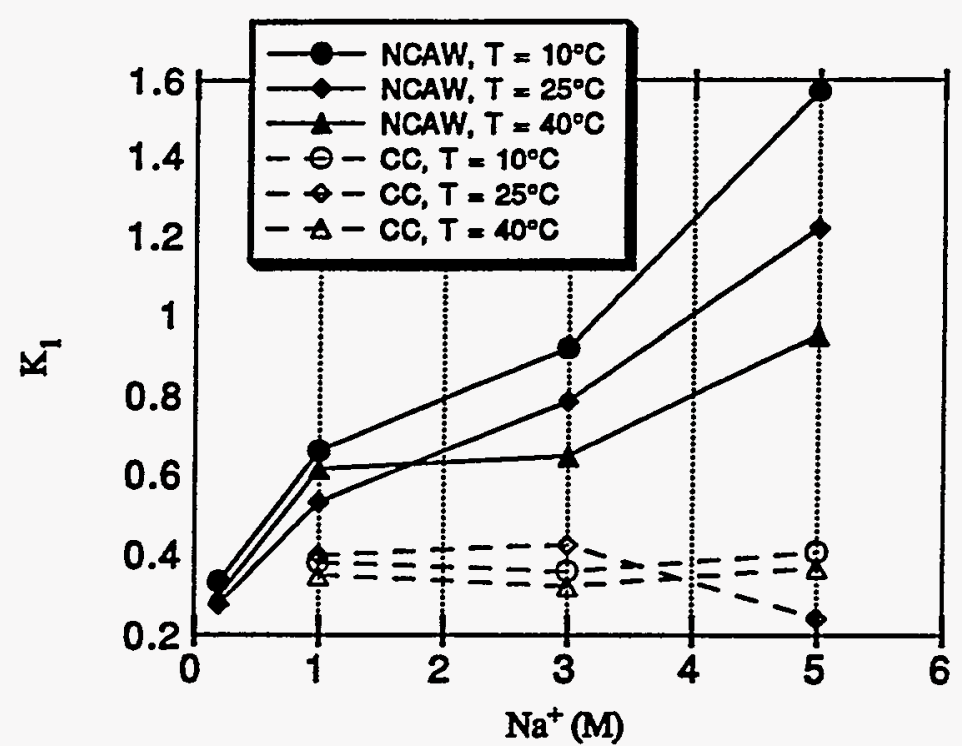

(a) Variation of $K_{1}$

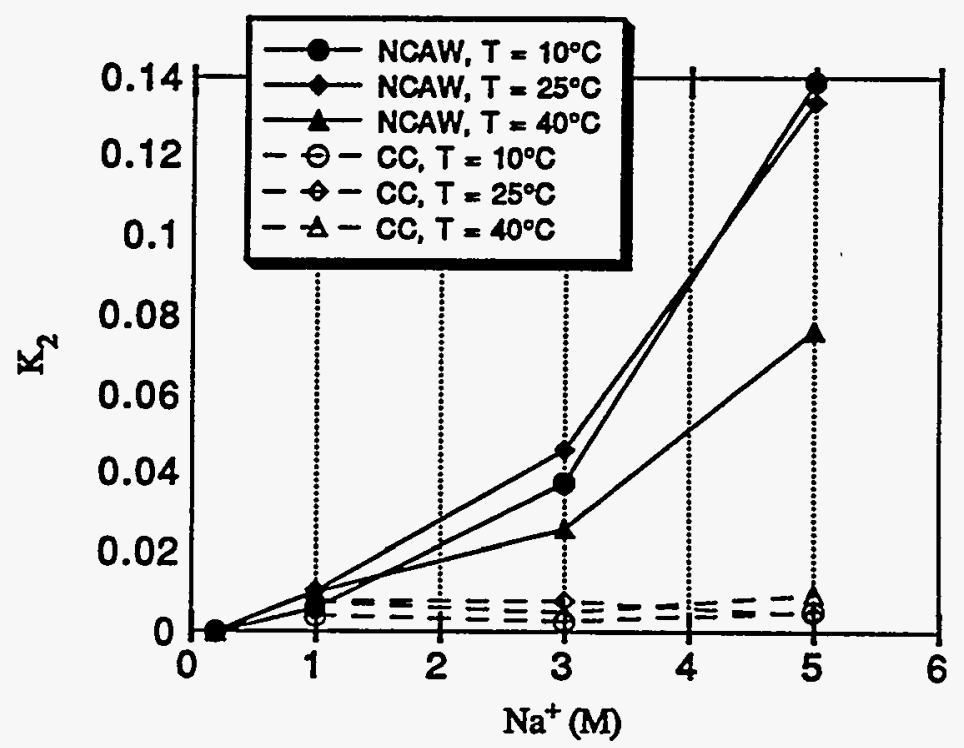

(b) Variation of $\mathrm{K}_{2}$

Figure 3.4. Variation of L-F parameters - Resorcinol-Formaldehyde Resin. 


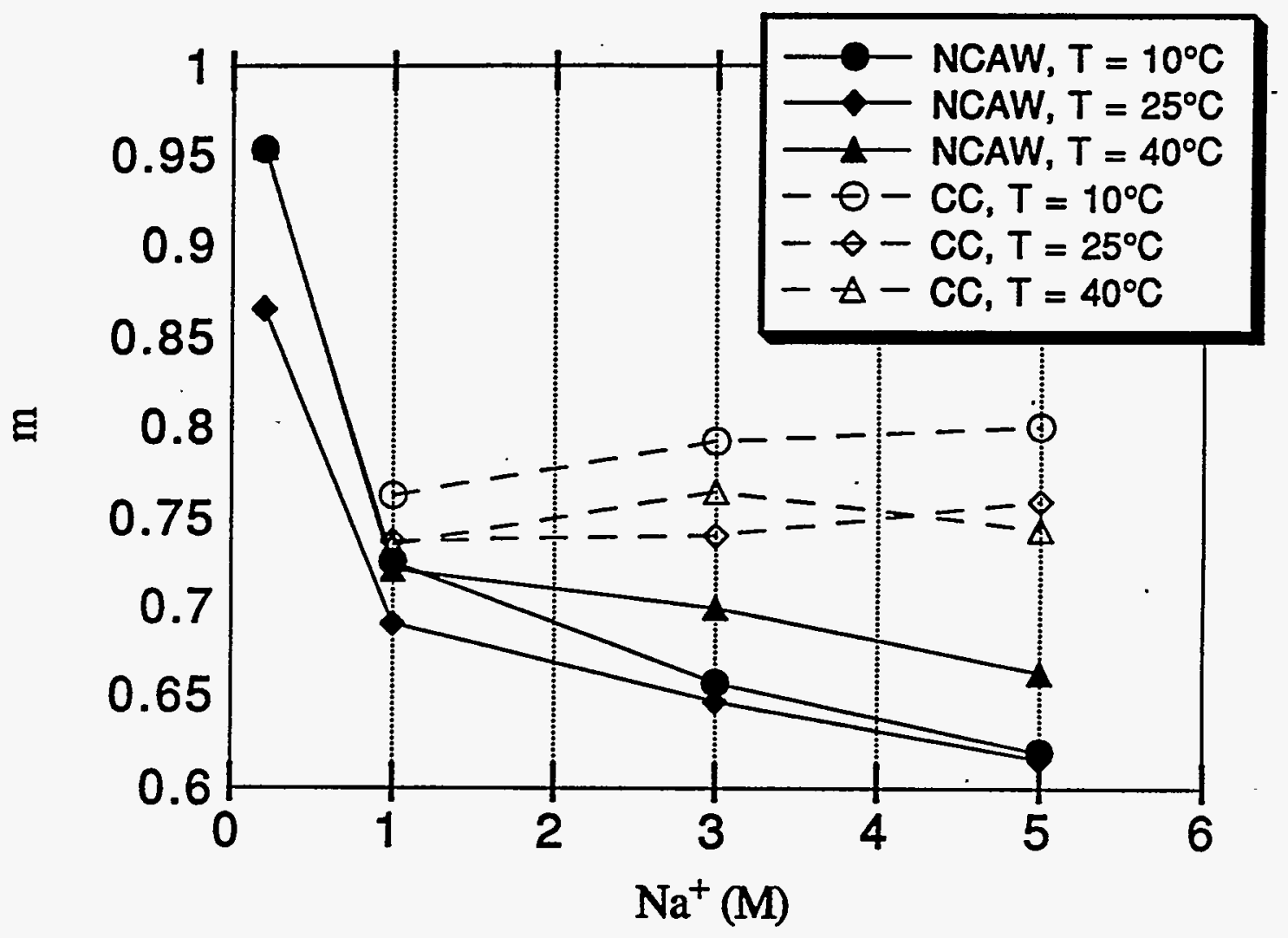

(c) Variation of $\mathrm{m}$

Figure 3.4 Variation of L-F parameters - Resorcinol-Formaldehyde Resin. 


\subsection{REFERENCES}

Bray, L. A., K. J. Carson, R. J. Elovich, and D. E. Kurath. 1992. Equilibrium Data for Cesium Ion Exchange of Hanford CC and NCAW Tank Waste. TWRSPP-92020, Pacific Northwest Laboratory, Richland, Hashington.

Freund7ich. 1926. Colloid and Capillary Chemistry. Dutton, New York.

Helfferich, F. 1962. Ion Exchange. McGraw-Hi11, New York.

Koble, R.A. and Thomas E. Corrigan. 1952. "Adsorption Isotherms for Pure Hydrocarbons." Industrial Engineering Chemistry. 44, p383-386, Jan-June.

Langmuir. 1916 Journal of American Chemical Society. 38, 221.

Samanta, S.K., M. Ramaswamy, B.M. Misra. 1992. "Studies on Cesium Uptake by

Phenolic Resins." Separation Science and Technology, 27(2). p 255-267. 


\section{APPENDIX A}

\section{CS-100 Equilibrium Data - Freundlich Isotherm}

A. 1 
Summary of Equilibrium Curve Fit Parameters: CS-100

\begin{tabular}{|c|c|c|c|c|}
\hline \multicolumn{5}{|c|}{$\begin{array}{l}\text { Cesium Ion Exchange Equilibrium Parameters (Freundlich Fit): } \\
\text { CS-100 Resin, NCAW Waste Simulant }\end{array}$} \\
\hline & $\mathrm{Na}+(\mathrm{M})$ & $T=10^{\circ} \mathrm{C}$ & $T=25^{\circ} \mathrm{C}$ & $\mathrm{T}=40^{\circ} \mathrm{C}$ \\
\hline $\begin{array}{l}K \\
n\end{array}$ & $\begin{array}{l}0.2 \\
0.2\end{array}$ & $\begin{array}{c}141.32 \\
0.86\end{array}$ & $\begin{array}{c}109.36 \\
0.88\end{array}$ & $\begin{array}{c}96.16 \\
0.91\end{array}$ \\
\hline $\begin{array}{l}\bar{K} \\
n\end{array}$ & $\begin{array}{l}1 \\
1\end{array}$ & $\begin{array}{c}35.99 \\
0.83\end{array}$ & $\begin{array}{c}27.33 \\
0.85\end{array}$ & $\begin{array}{c}23.85 \\
0.88\end{array}$ \\
\hline $\begin{array}{l}\mathrm{K} \\
\mathrm{n}\end{array}$ & $\begin{array}{l}3 \\
3\end{array}$ & $\begin{array}{c}13.68 \\
0.81\end{array}$ & $\begin{array}{c}11.45 \\
0.83\end{array}$ & $\begin{array}{l}22.85 \\
0.96\end{array}$ \\
\hline $\begin{array}{l}K \\
n\end{array}$ & $\begin{array}{l}5 \\
5\end{array}$ & $\begin{array}{c}10.31 \\
0.80\end{array}$ & $\begin{array}{l}9.65 \\
0.83\end{array}$ & $\begin{array}{l}5.91 \\
0.81\end{array}$ \\
\hline
\end{tabular}

Cesium Ion Exchange Equilibrium Parameters (Freundlich Fit): CS-100 Resin, CC Waste Simulant

\begin{tabular}{|c|c|c|c|c|}
\hline & $N a+(M)$ & $T=10^{\circ} \mathrm{C}$ & $T=25^{\circ} \mathrm{C}$ & $T=40^{\circ} \mathrm{C}$ \\
\hline$K$ & 3 & 17.80 & 14.74 & 10.67 \\
$m$ & 3 & 0.84 & 0.87 & 0.88 \\
\hline$K$ & 5 & 25.75 & 18.27 & 10.73 \\
$m$ & 5 & 0.88 & 0.89 & 0.89 \\
\hline$K$ & 7 & 6.88 & 8.89 & 6.50 \\
$m$ & 7 & 0.80 & 0.85 & 0.86 \\
\hline
\end{tabular}



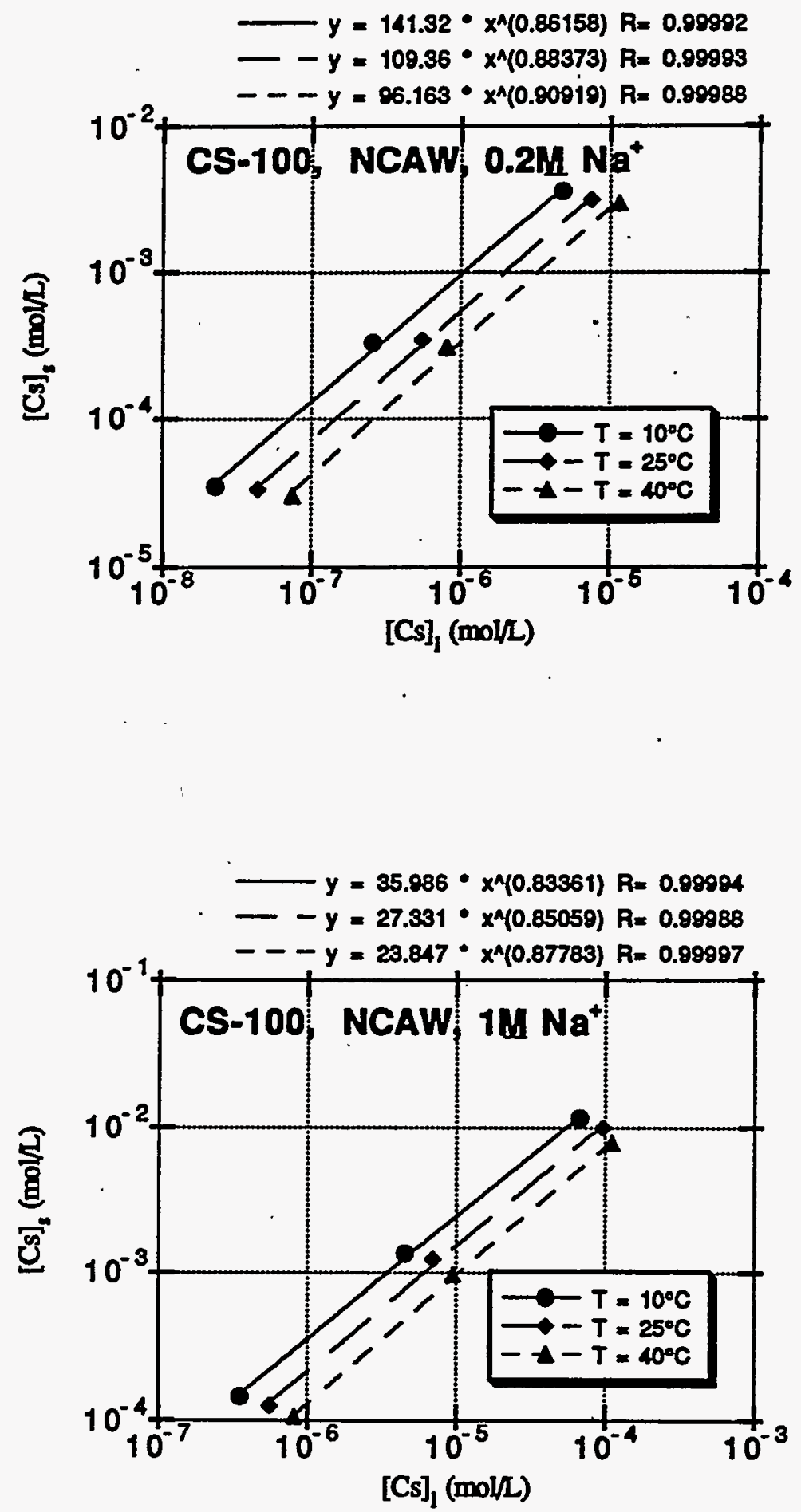

A. 3 

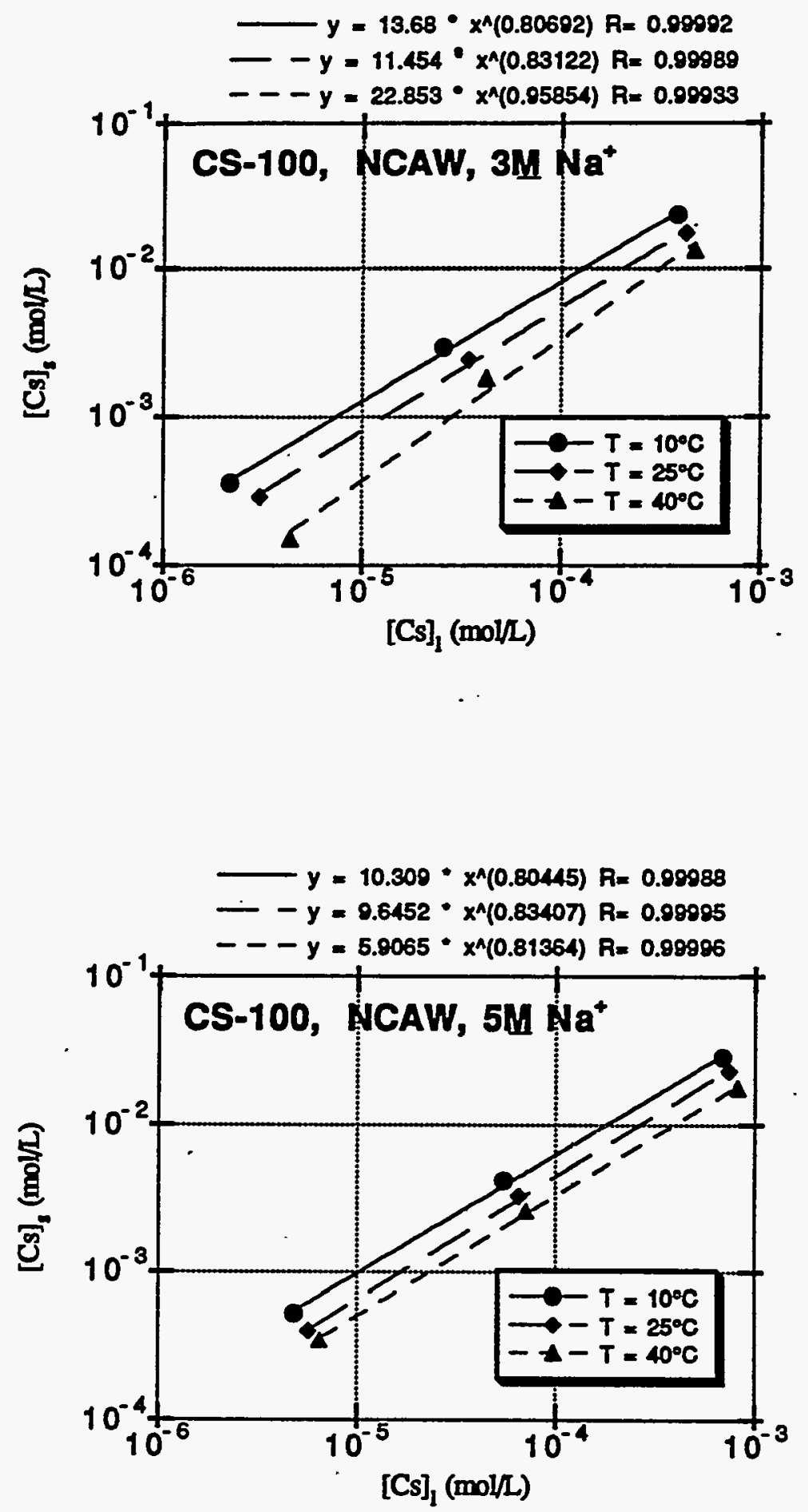

A. 4 

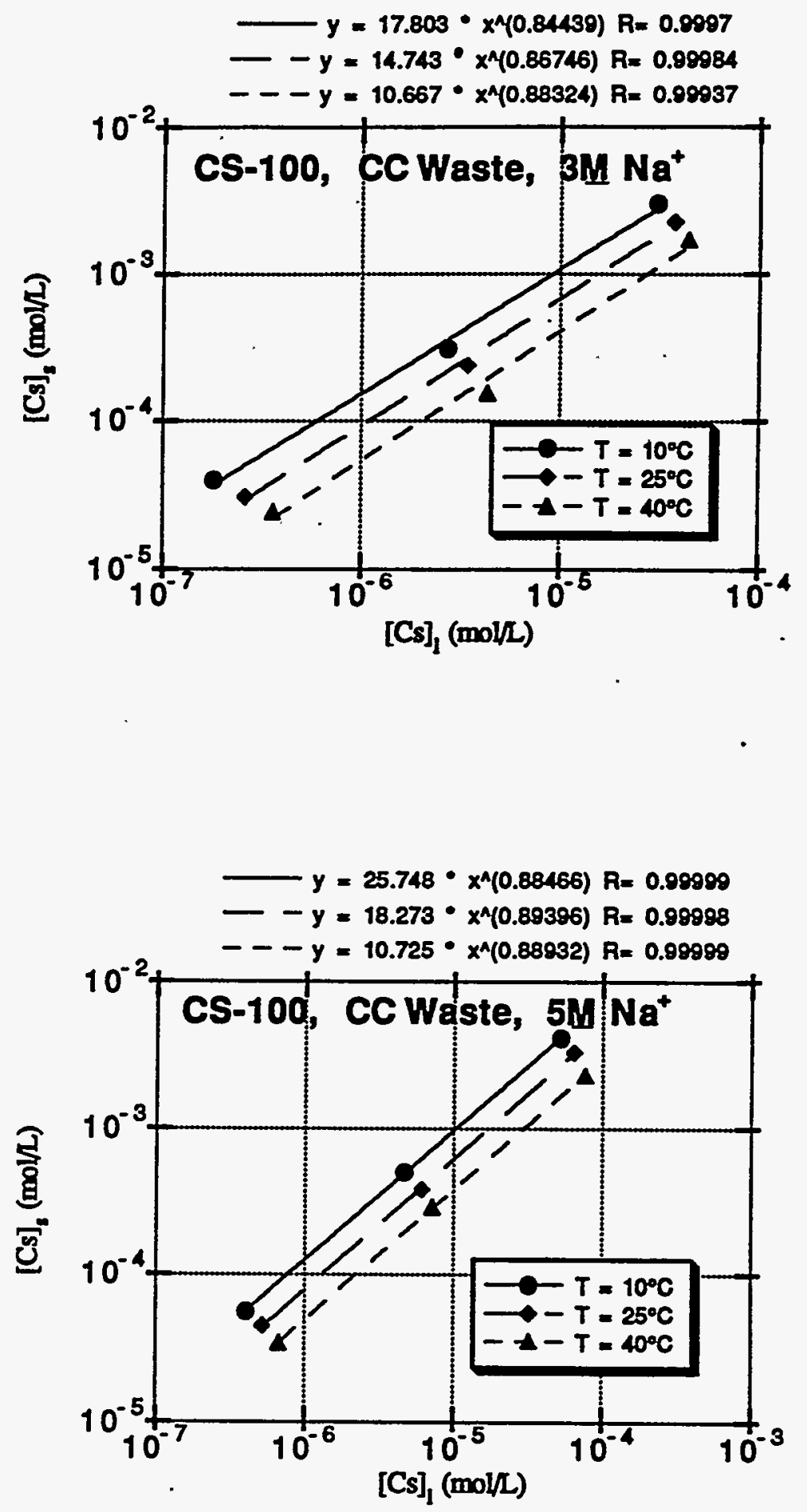

A. 5 


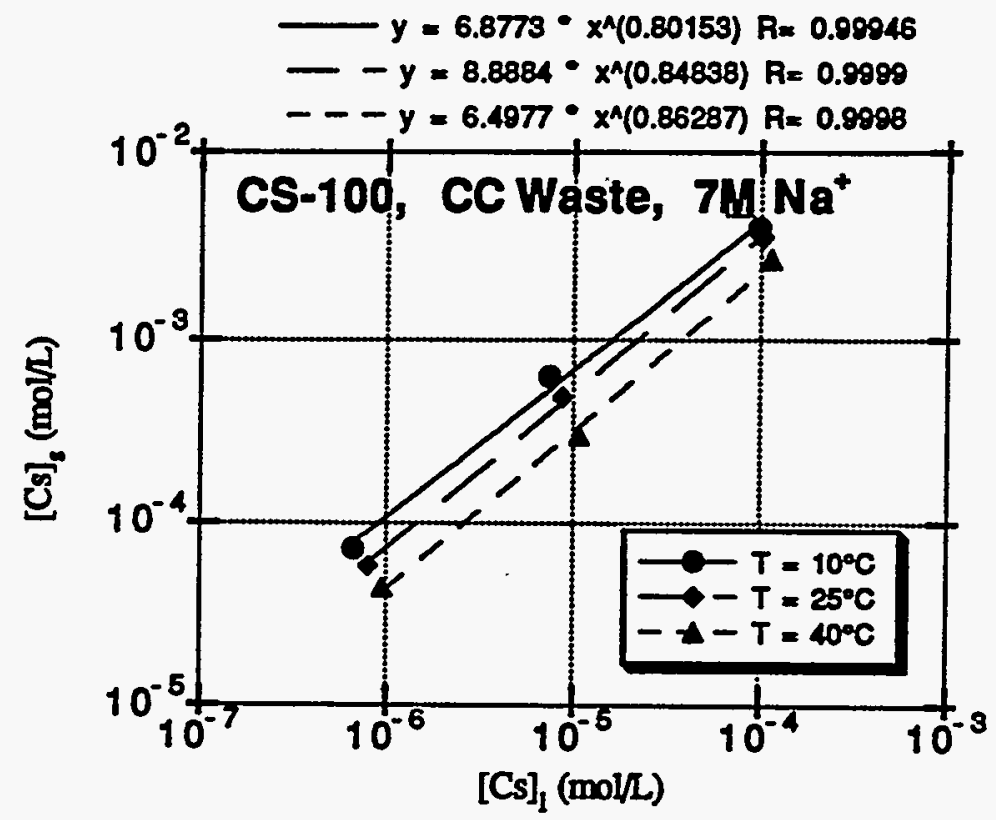

A. 6 

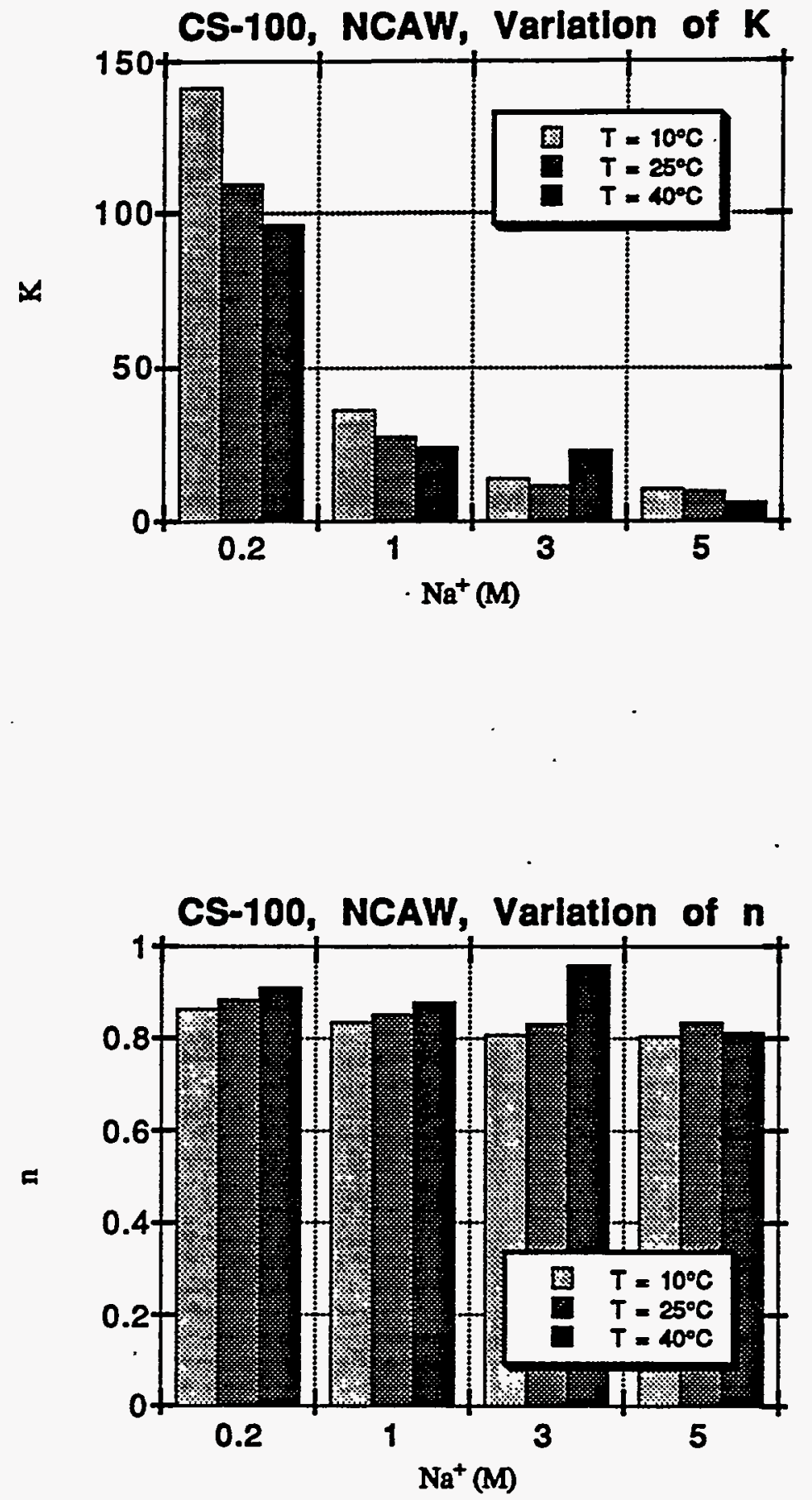

A. 7 

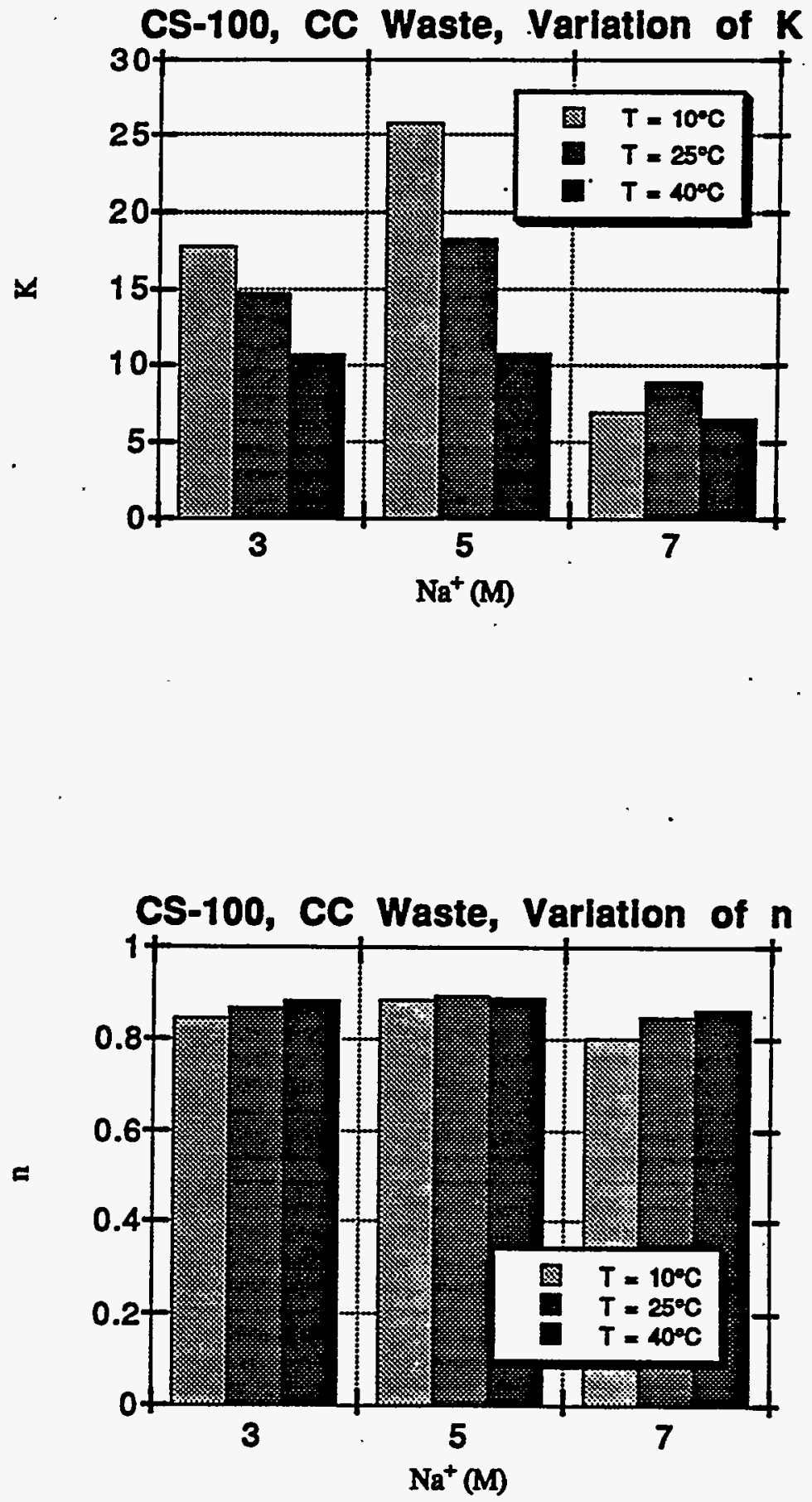

A. 8 


\section{APPENDIX B}

Resorcinol-Formaldehyde Equilibrium Data - Langmuir-Freundlich Isotherm

B.1 
Summary of Equilibrium Curve Fit Parameters:

Resorcinol-Formaldehyde Resin

Cesium lon Exchange Equilibrium Parameters (Combination LangmuirFreundlich Fit): Resorcinol-Formaldehyde Resin, NCAW Simulant

\begin{tabular}{|c|c|c|c|c|}
\hline & $\mathrm{Na}+(\mathrm{M})$ & $T=10^{\circ} \mathrm{C}$ & $\mathrm{T}=25^{\circ} \mathrm{C}$ & $T=40^{\circ} \mathrm{C}$ \\
\hline $\mathrm{K} 1$ & & $3.34 \mathrm{E}-01$ & $2.78 \mathrm{E}-01$ & $2.99 \mathrm{E}-01$ \\
$\mathrm{~K} 2$ & 0.2 & $3.09 \mathrm{E}-05$ & $1.59 \mathrm{E}-04$ & $6.11 \mathrm{E}-05$ \\
$\mathrm{~m}$ & & $9.53 \mathrm{E}-01$ & $8.66 \mathrm{E}-01$ & $9.55 \mathrm{E}-01$ \\
\hline $\mathrm{K} 1$ & & $6.61 \mathrm{E}-01$ & $5.36 \mathrm{E}-01$ & $6.17 \mathrm{E}-01$ \\
$\mathrm{~K} 2$ & 1 & $5.94 \mathrm{E}-03$ & $1.03 \mathrm{E}-02$ & $1.02 \mathrm{E}-02$ \\
$\mathrm{~m}$ & & $7.25 \mathrm{E}-01$ & $6.91 \mathrm{E}-01$ & $7.22 \mathrm{E}-01$ \\
\hline $\mathrm{K} 1$ & & $9.19 \mathrm{E}-01$ & $7.85 \mathrm{E}-01$ & $6.47 \mathrm{E}-01$ \\
$\mathrm{~K} 2$ & 3 & $3.77 \mathrm{E}-02$ & $4.60 \mathrm{E}-02$ & $2.61 \mathrm{E}-02$ \\
$\mathrm{~m}$ & & $6.58 \mathrm{E}-01$ & $6.48 \mathrm{E}-01$ & $7.00 \mathrm{E}-01$ \\
\hline $\mathrm{K} 1$ & & $1.57 \mathrm{E}+00$ & $1.22 \mathrm{E}+00$ & $9.52 \mathrm{E}-01$ \\
$\mathrm{~K} 2$ & 5 & $1.39 \mathrm{E}-01$ & $1.34 \mathrm{E}-01$ & $7.64 \mathrm{E}-02$ \\
$\mathrm{~m}$ & & $6.20 \mathrm{E}-01$ & $6.16 \mathrm{E}-01$ & $6.64 \mathrm{E}-01$ \\
\hline
\end{tabular}

Cesium Ion Exchange Equilibrium Parameters (Combination LangmuirFreundlich Fit): Resorcinol-Formaldehyde Resin, CC Waste Simulant

\begin{tabular}{|c|c|c|c|c|}
\hline & $\mathrm{Na}+(M)$ & $\mathrm{T}=10^{\circ} \mathrm{C}$ & $\mathrm{T}=25{ }^{\circ} \mathrm{C}$ & $\mathrm{T}=40^{\circ} \mathrm{C}$ \\
\hline $\mathrm{K} 1$ & & $3.83 \mathrm{E}-01$ & $4.02 \mathrm{E}-01$ & $3.52 \mathrm{E}-01$ \\
$\mathrm{~K} 2$ & 3 & $4.13 \mathrm{E}-03$ & $7.90 \mathrm{E}-03$ & $7.59 \mathrm{E}-03$ \\
$\mathrm{~m}$ & & $7.62 \mathrm{E}-01$ & $7.37 \mathrm{E}-01$ & $7.35 \mathrm{E}-01$ \\
\hline $\mathrm{K} 1$ & & $3.61 \mathrm{E}-01$ & $4.28 \mathrm{E}-01$ & $3.24 \mathrm{E}-01$ \\
$\mathrm{~K} 2$ & 5 & $2.81 \mathrm{E}-03$ & $7.82 \mathrm{E}-03$ & $4.99 \mathrm{E}-03$ \\
$\mathrm{~m}$ & & $7.93 \mathrm{E}-01$ & $7.40 \mathrm{E}-01$ & $7.64 \mathrm{E}-01$ \\
\hline $\mathrm{K} 1$ & & $4.10 \mathrm{E}-01$ & $2.43 \mathrm{E}-01$ & $3.70 \mathrm{E}-01$ \\
$\mathrm{~K} 2$ & 7 & $5.21 \mathrm{E}-03$ & $4.52 \mathrm{E}-03$ & $9.70 \mathrm{E}-03$ \\
$\mathrm{~m}$ & & $8.01 \mathrm{E}-01$ & $7.59 \mathrm{E}-01$ & $7.43 \mathrm{E}-01$ \\
\hline
\end{tabular}



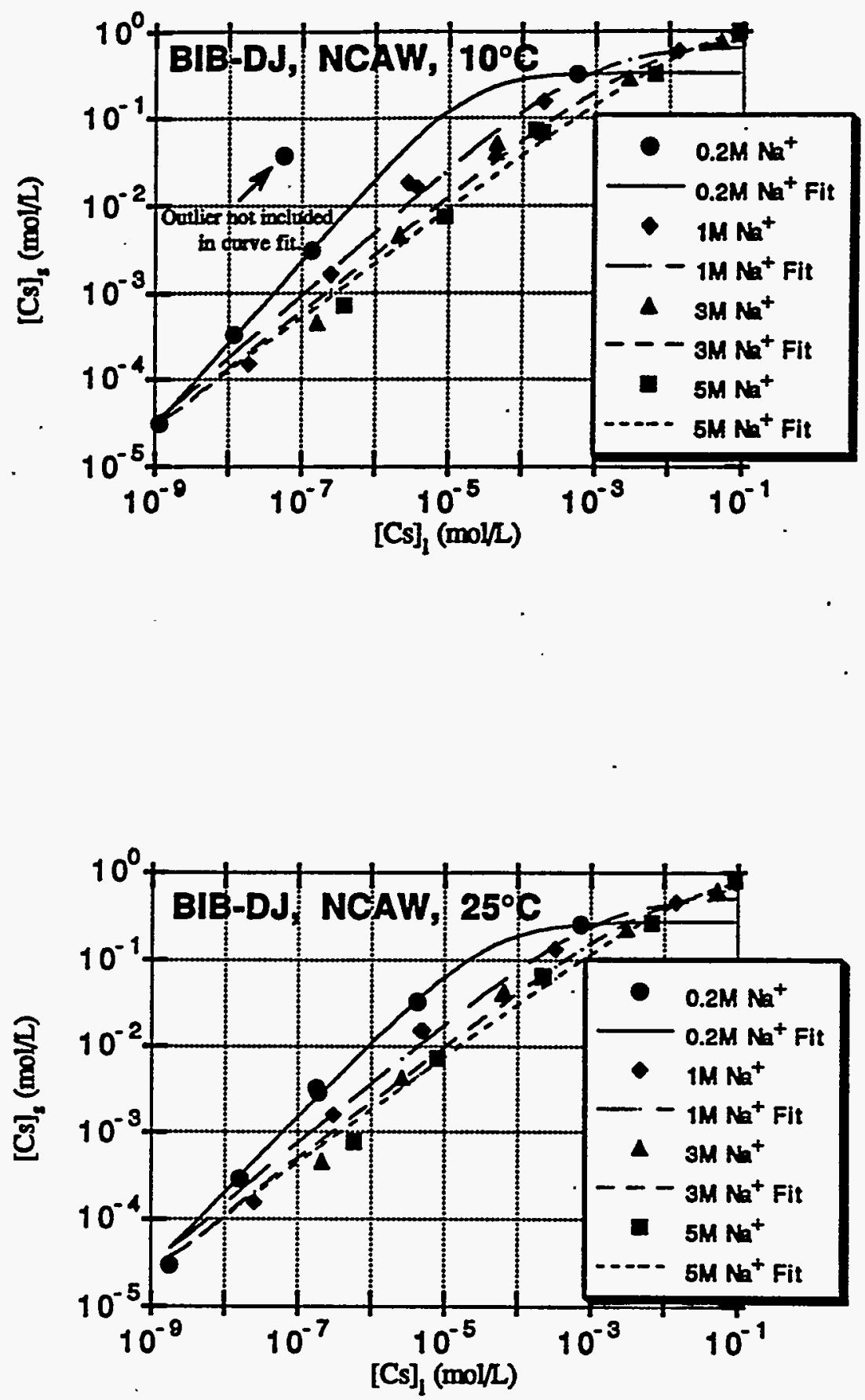

B. 3 


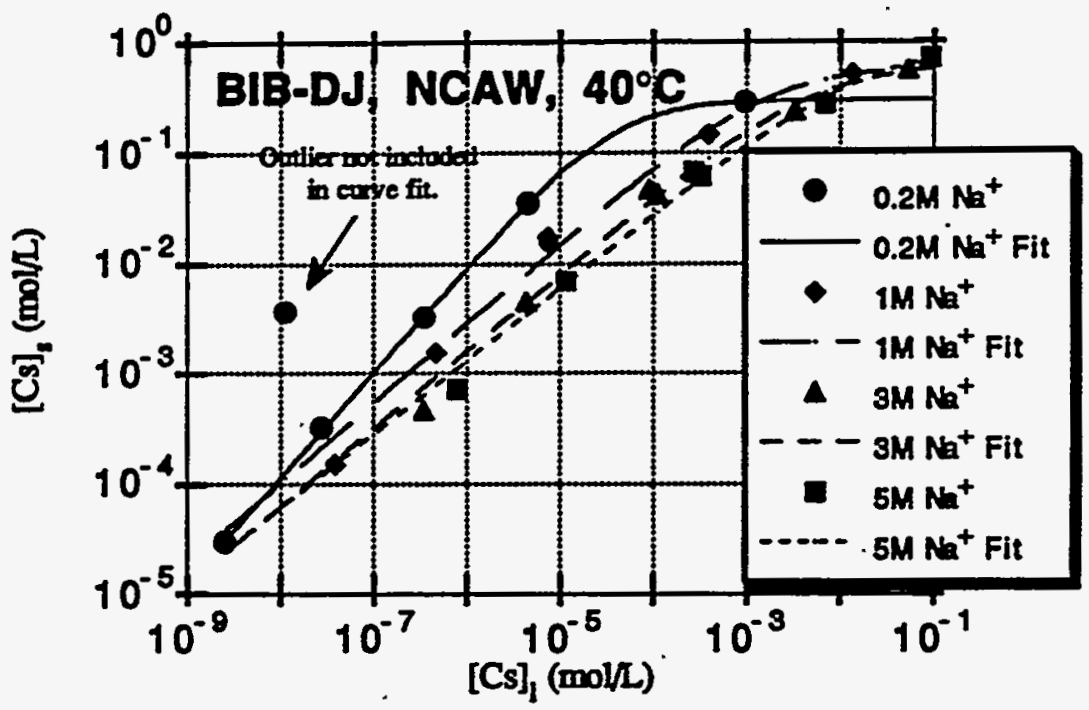

B. 4 

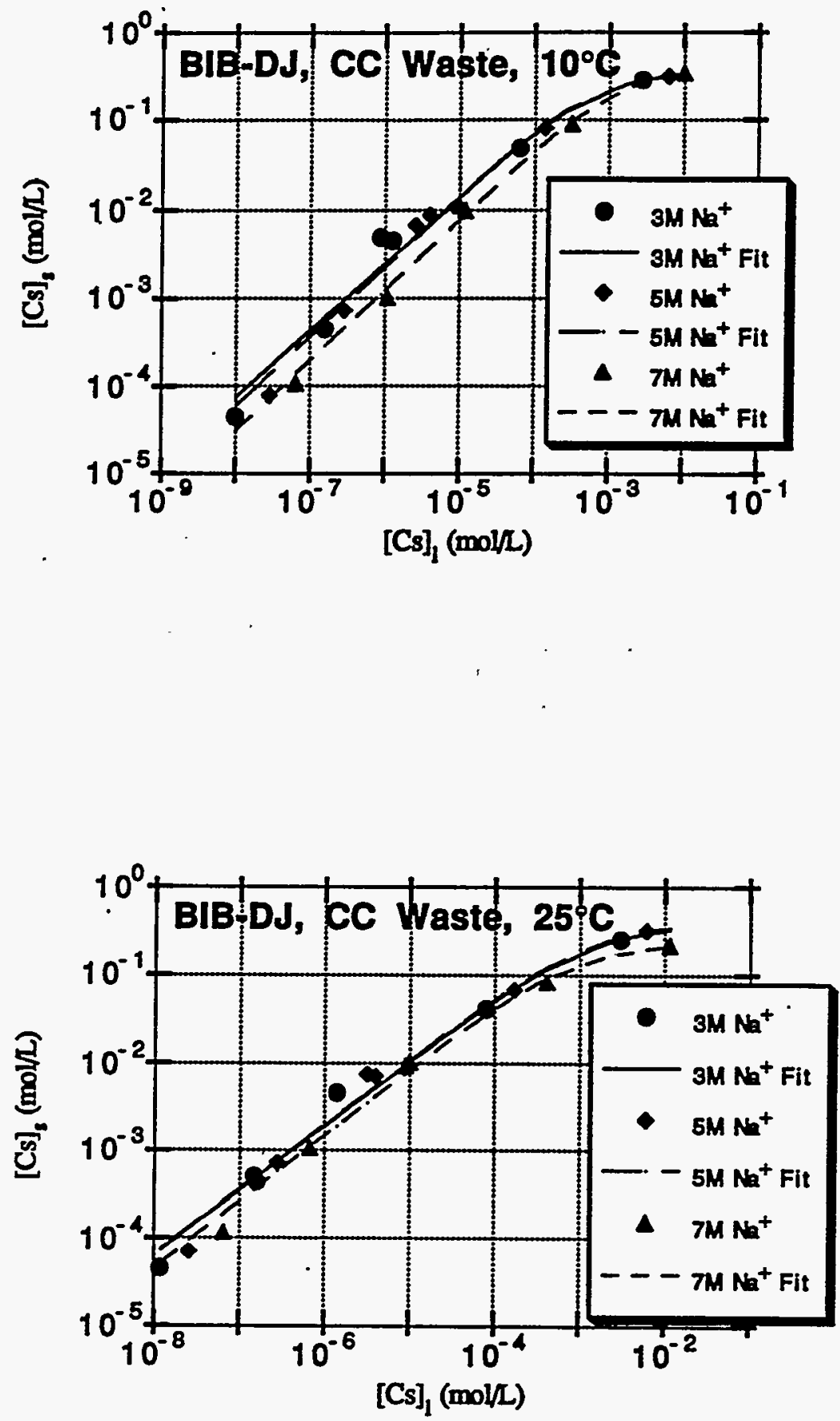

B. 5 


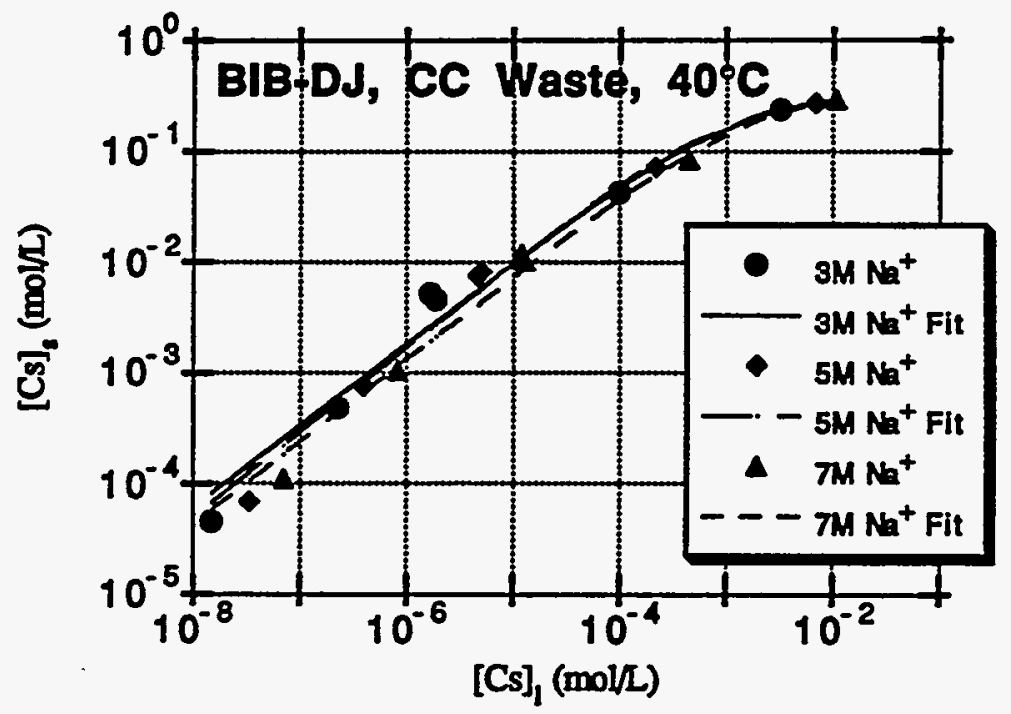

B. 6 

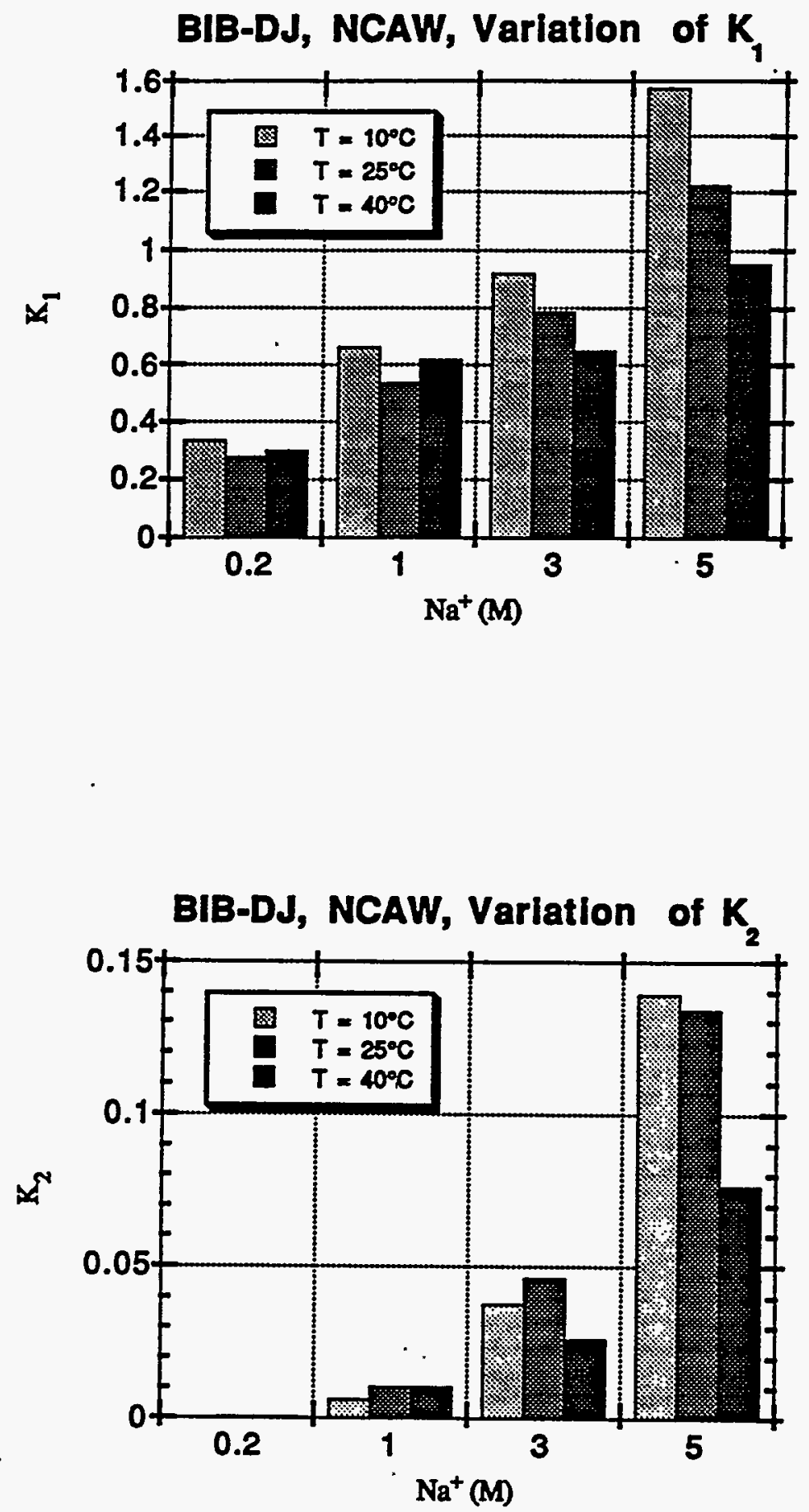

B. 7 


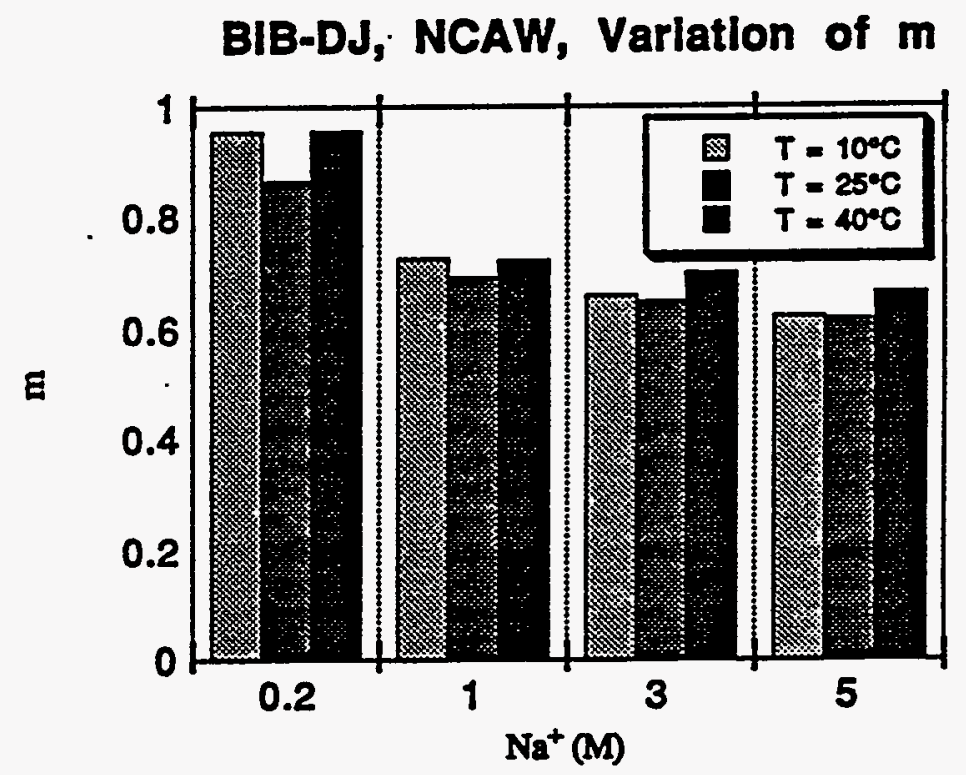

B. 8 

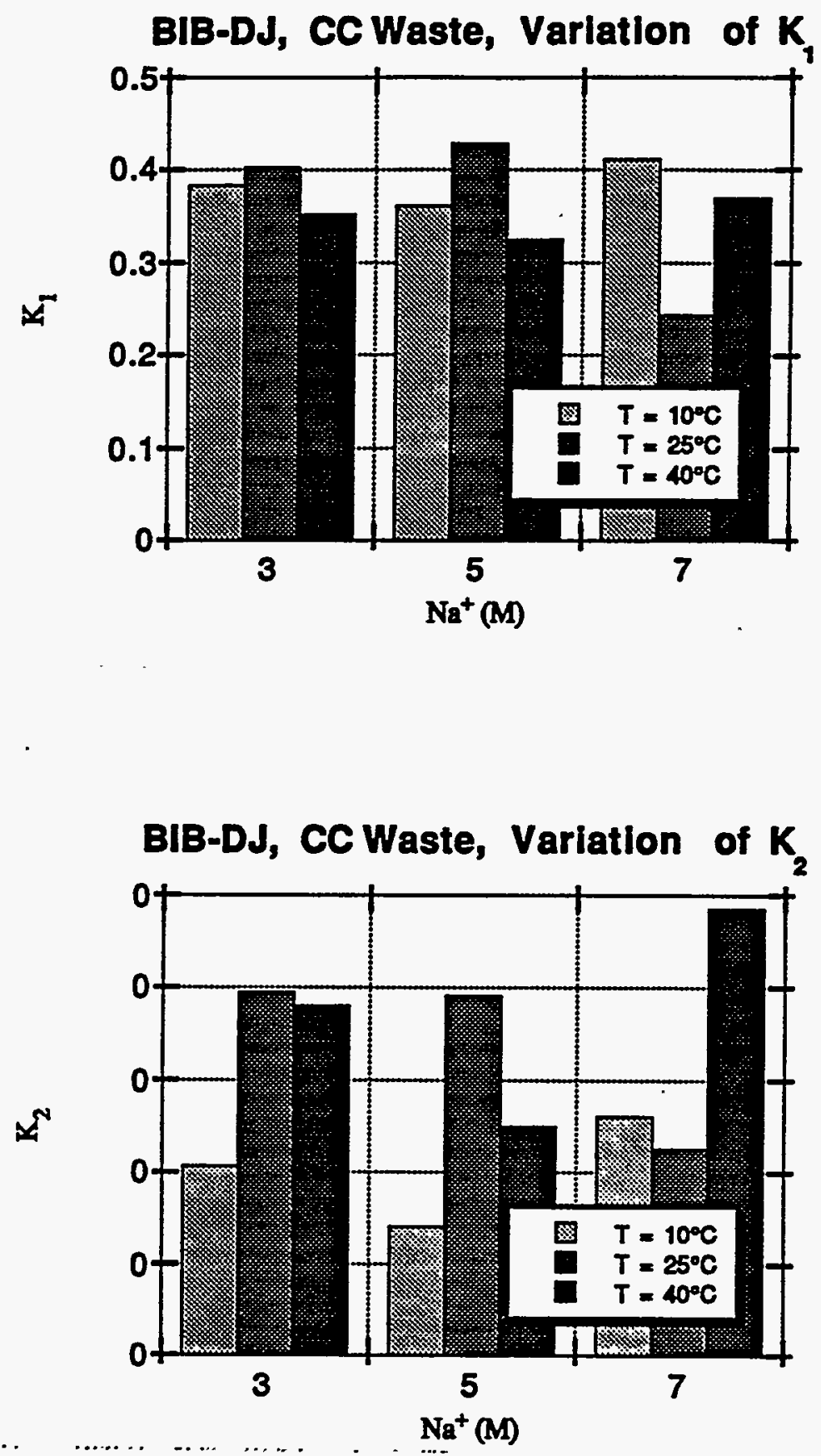

B. 9 
BIB-DJ, CC Waste, Variation of $\mathbf{m}$

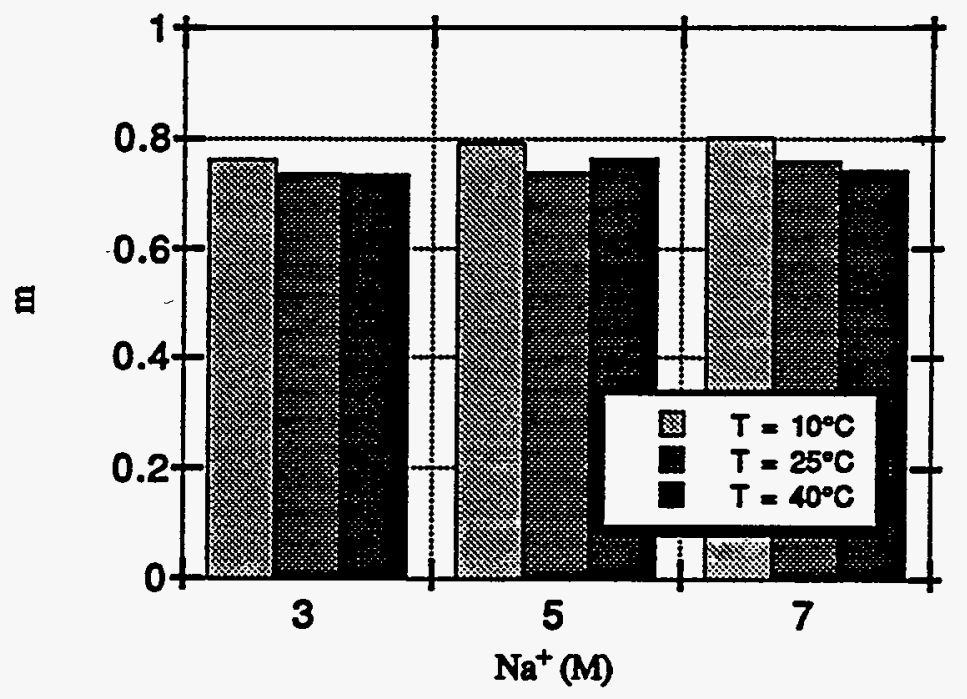

B. 10 